$$
\text { MT-DP - 2013/43 }
$$

\title{
On the mobilizing role of social media in revolutions: a game-theoretic approach
}

HUBERT JÁNOS KISS - ALFONSO ROSA-GARCÍA 
Discussion papers

MT-DP - 2013/43

Institute of Economics, Centre for Economic and Regional Studies,

Hungarian Academy of Sciences

KTI/IE Discussion Papers are circulated to promote discussion and provoque comments. Any references to discussion papers should clearly state that the paper is preliminary. Materials published in this series may subject to further publication.

On the mobilizing role of social media in revolutions: a game-theoretic approach

\author{
Authors: \\ Hubert János Kiss \\ research fellow \\ in the Momentum(LD-004/2010) Game Theory Research Group \\ Institute of Economics, \\ Centre for Economic and Regional Studies \\ Hungarian Academy of Sciences and \\ Eötvös Loránd University - Department of Economics \\ and Affiliate Fellow at CERGE-EI, Prague \\ email: kiss.hubert.janos@krtk.mta.hu \\ Alfonso Rosa-García \\ Facultad de Ciencias Jurídicas y de la Empresa, \\ Universidad Católica San Antonio. \\ Murcia, Spain \\ email: arosa@ucam.edu
}

December 2013 


\title{
On the mobilizing role of social media in revolutions: a game-theoretic approach
}

\author{
Hubert János Kiss - Alfonso Rosa-García
}

\begin{abstract}
A distinctive feature of recent revolutions was the key role of social media (e.g. Facebook, Twitter and YouTube). We study the role of social media in mobilization. In a simple model we assume that while social media allow to observe all previous decisions, mass media only give aggregate information about the state of a revolt. We show that when individuals' willingness to revolt is publicly known, then both sorts of media foster a successful revolution. However, when willingness to revolt is private information, only social media ensure that a revolt succeeds, with mass media multiple outcomes are possible. This suggests that social media enhance the likelihood that a revolution triumphs more than traditional mass media.
\end{abstract}

Keywords: social media, mass media, revolution, coordination game, sequential games

JEL Classiffication: C72, D02, D74 


\title{
A közösségi média mozgósító szerepe a forradalmakban: egy játékelméleti megközelítés
}

\author{
Kiss Hubert János - Alfonso Rosa-García
}

Összefoglaló

A közelmúltbeli forradalmak egyik egyedi jegye volt a közösségi média (például Facebook, Twitter és YouTube) kulcsszerepe. A közösségi média szerepét vizsgájuk a mozgósításban. Egy egyszerű modellben feltesszük, hogy a közösségi média segítségével megfigyelhető az összes korábbi döntés, míg a tömegtájékoztatás csak összesített információt ad a felkelés állapotáról. Ha az egyének rezsimváltó hajlandósága mindenki által ismert, akkor mindkét fajta média elősegíti a sikeres forradalmat. Azonban, amikor a rezsimváltó hajlandóság magáninformáció, akkor csupán a közösségi média segíti elő a sikeres forradalmat, a tömegtájékoztatás segítségével több kimenetel is lehetséges. Ez arra utal, hogy a közösségi média jobban megnöveli a forradalmak sikerességét, mint a hagyományos tömegtájékoztatás.

Tárgyszavak: közösségi média, tömegtájékoztatás, forradalom, koordinációs játék, szekvenciális játék

JEL kódok: C72, D02, D74 


\title{
On the mobilizing role of social media in revolutions: a game-theoretic approach
}

\author{
Hubert Janos Kiss*- Alfonso Rosa-García ${ }^{\dagger}$
}

4th December 2013

\begin{abstract}
A distinctive feature of recent revolutions was the key role of social media (e.g. Facebook, Twitter and YouTube). We study the role of social media in mobilization. In a simple model we assume that while social media allow to observe all previous decisions, mass media only give aggregate information about the state of a revolt. We show that when individuals' willingness to revolt is publicly known, then both sorts of media foster a successful revolution. However, when willingness to revolt is private information, only social media ensure that a revolt succeeds, with mass media multiple outcomes are possible. This suggests that social media enhance the likelihood that a revolution triumphs more than traditional mass media.
\end{abstract}

Keywords: social media, mass media, revolution, coordination game, sequential games

JEL Classification: C72, D02, D74

\section{Introduction}

"We use Facebook to schedule protests, Twitter to coordinate, and YouTube to tell the world." (Anonymous Cairo Activist)

In recent years there were many demonstrations that attracted considerable public attention internationally. The mass protests that started the uprisings against the regimes in the Arab world, the demonstrations of the indignados movement in Spain or the Occupy movement worldwide are the most prominent examples. A distinguishing feature of these events was the omnipresence of social media (especially, Facebook, Twitter and YouTube). Many scholars

\footnotetext{
*Eötvös Loránd University - Department of Economics; Research fellow in the "Momentum" (LD-004/2010) Game Theory Research Group Institute of Economics Centre for Economic and Regional Studies of the Hungarian Academy of Sciences; and Affiliate Fellow at CERGE-EI, Prague. Email: kiss.hubert.janos@krtk.mta.hu

${ }^{\dagger}$ Facultad de Ciencias Jurídicas y de la Empresa, Universidad Católica San Antonio. Murcia, Spain. Email: arosa@ucam.edu
} 
wonder how these new information technologies affect social movements. Do they help to overthrow autocratic regimes more easily or do they help promote social issues more than the former technology? (e.g. [3]).

Social media affect the evolution of protests in various ways. Social media help to inform audiences around the world about the unfolding of the events, attracting international attention and provoking diplomatic pressure. These new technologies also offer an easy, quick and inexpensive means of communication that helps to spread information among the participants. However, it should also be noted that social media are also used by the repressive regimes. Autocratic regimes control the Internet to a large extent. For instance, during the Arab spring several times the governments just shut Internet down for days, they actively monitor chats and forums and also develop fake websites to attract and identify potential opponents (see chapter 4 in [4]).

In this paper we focus on the role of social media in mobilizing the masses in an autocratic regime. That is, we concentrate on how these new technologies may help that successful massive protests are organized in countries where this kind of demonstrations were rare before. We argue that a potential channel for the success of these protests is that social media provide such a detailed structure of information that makes that the coordination game that the discontented citizens play has a unique equilibrium. Mass media (e.g. TV, radio) - even if not manipulated by the regime - lead to multiple equilibria in our main setup. Our approach is game-theoretical, we use standard equilibrium concepts to obtain the results. Our contribution to the existing literature is that we show rigorously that there is a qualitative difference between mass and social media in mobilization, the latter being able to promote mobilization more efficiently.

Efficient mobilization is a key factor to achieve the goals of any movement. Mobilization relies on the channels of communication and the flow of information that enable dissidents to organize themselves and engage in collective action. Hence, communication and the technologies that make it possible play a crucial role in mobilization. We present a model that explains how mass and social media affect mobilization when it is known that there are enough willing individuals to overthrow the dictator. Our starting point is that willingness to participate in the protests depends on the perceived costs and benefits of participation. Arguably, heading out onto the streets implies the costs of facing tear gas, rubber bullets and potential arrest and incarceration. Benefits involve the perceived gains in participating in an uprising that may bring about a better future, provided it succeeds. The probability of success is highly related to the number of participants. Yet, when a potential protester decides whether to participate, possibly she has only a vague idea about if sufficient other people will participate. Different types of media may affect these expectations (and the resulting mobilization) in diverse ways.

We posit that when an individual obtains information through mass media then she gets to know the actual state of the revolution in that moment, whereas when informed via social media she is able to observe the sequence of decisions leading up to that state. For instance, when a search in Twitter is realized, the individual gets the last conversations about the topic, and by scrolling down the 
page she is able to see all previous tweets about it. In Facebook, the users may comment on the events and all previous comments can be read. We suppose that tweets and comments are informative about the individuals' decision to join the protests or to stay at home. By contrast, when TV or radio inform about the state of a given event, the precise history remains hidden, only aggregate information about the turnout is reported.

We model the problem of revolution as a coordination problem. We suppose that there are two groups in the society: one consists of individuals who want to overthrow the dictator (willing individuals) and the another one is composed of individuals who do not want to change the regime (unwilling individuals). We assume that there are enough willing individuals to bring about a change. That is, if all of them revolt, then the dictator is overthrown. However, if the number of protesters (those willing individuals who actually head onto the streets) falls short of a critical mass, then the dictator remains in power and may punish those who participated in the failed revolt. We assume that individuals choose consecutively if they want to take part in the revolt or not, and the order of decisions is randomly selected. Before decision, each individual is informed about the state of the revolution. When this information is channeled through mass media, the individual learns how many people have already chosen to participate (i.e. the actual state of the revolution). The difference when informed through the social media is that individuals observe each of the past decisions (e.g. the precise history).

First, we show that when the type of individuals (that is, if she is willing to revolt or not) is public information and they are informed through any of the communication technologies, each willing individual takes part in the revolution and, thus, it is successful. However, it is not necessarily the case when the individuals receive no information about the state of the revolution. This result indicates that the mere existence of communication technologies (that are not manipulated) enabling to spread information facilitates that social movements achieve their objective. Without the communication technologies individuals play a simultaneous game that has multiple equilibria.

Second, we study a more realistic setup in which the type of individuals is not observed (i.e. it is private information). We assume that individuals know that there are enough individuals to change the regime, but they do not know who the willing individuals are. Under these circumstances, the type of communication technology becomes relevant. We prove that mass media do not necessarily enable willing individuals to organize themselves efficiently. Thus, depending on the perceived costs and benefits willing individuals possibly choose not to revolt. However, successful revolution is the unique equilibrium outcome when willing individuals use social media, independently of the severity of punishment that protesters may suffer if they fail to overthrow the dictator. This result shows that communication through social media facilitates that revolutions succeed more than when communication is channeled through traditional mass media.

Although our comparison of mass and social media suggests that they are competing communication technologies, our results can be interpreted as answering the question about how social media enhance mass media's ability to 
mobilize individuals. In this respect, our findings shed light on the differential effect that social media have compared to the traditional mass media.

Section 2 reviews briefly the relevant literature. Section 3 presents the model and the results. In Section 4 we discuss two examples and Section 5 concludes. All the proofs are relegated to the Appendix.

\section{Literature Review}

Our interpretation of the process why an individual joins a protests follows the rationalist view that the citizens assess the costs and benefits of participating in a revolt (see, for instance, [7] and the references therein). A key issue in the rational school is why citizens join revolutions. Social networks play an important role at several stages of the process. [14] distinguishes three functions of social networks: socialization, structural-connection function and decisionshaping function. Social media create social networks that are important in community creation, in connecting the prospective participants and also in the decision-making, since individuals use the information coming from the social network to anticipate and evaluate the potential costs and outcome of participation. Most importantly, the decision to join the revolution depends on the intentions and action of other participants. If many other citizens are expected to join, then the revolution is likely to succeed and this makes participation more attractive. In the opposite case, staying at home may be the optimal decision. Hence, the decision is strategical, because it depends on the behavior of others. Both mass and social media enable individuals to form beliefs about the turnout at the protest, but they differ in the degree of how detailed the information is. We show that social media promote better mobilization, because from an individual's point of view they give more accurate information about previous decisions and they allow that subsequent individuals observe the decision.

[1] studies the role of vanguards that shifts the equilibrium from no revolution into one in which citizens revolt. The vanguard uses violence and it is informative about the discontent in the society and individuals sensing the increased dissatisfaction are more likely to join the revolution. We do not consider vanguards, the observability of actions determines whether the individuals desiring a regime change coordinate successfully or not. In this sense, [2] is the paper that is closest to ours in spirit. Chwe analyzes the minimal conditions that make coordination feasible among willing individuals, regardless of the prior beliefs about the willingness of the others. To do so, he considers only the state of the world in which everybody is willing. As a consequence, when somebody stays at home, then it is known that it was a willing individual. In our model, both types are present and the main difficulty comes from what a willing individual believes when observing that somebody stays at home. We argue that social media allow to infer the type of the individual that stayed at home and this helps to avoid coordination failure, whereas mass media fails to do so. The logic behind the inference is easy: if given a history of past decisions a willing 
individual's optimal decision was to join the protest, but the citizen stayed at home, then it must be an unwilling citizen.

The aim of this paper is to show that differences between the information transmitted by mass and social media make that the latter makes the revolution triumph. This seems to suggest that social media is a catalyst for a regime change. However, the empirical evidence is not unambigous. For instance, while the demonstrations organized through Facebook were extremely successful in Egypt in January 2011, in 2008 the April 6 Youth Movement failed to trigger mass protests in the same country. In 2011, in Syria the "days of rage" protest was endorsed by 12000 individuals online, but nothing happened. It shows that a problem of commitment (supporting an event on Facebook, but not attending it) may arise in the Internet. ${ }^{1}$ A possibly even more severe issue is that media (both mass and social) may be manipulated by the regime. Edmond (2013) studies the revolution also as a coordination game, but in his paper the regime can actively manipulate the information. Using global games technique, he shows that the game has a unique equilibrium. In fact, regimes controlled tightly the Internet, but the control differed across countries, for example in Mubarak's Egypt Internet was less censored, than in Tunisia ([4]). As already mentioned, Facebook, Twitter and even Internet was cut off by the government in some cases. The autocratic regimes' response also changed after the successful revolutions, repression grew in Algeria and Lybia to prevent uprisings there. Clearly, the mere existence of social media is not enough to bring about a regime change. In this paper, we show how it can contribute to a successful revolution through enabling more efficient mobilization.

The descriptions of the recent revolutions reveals why social media are better to promote mobilization. The basic problem is that individuals fear that not enough people will go to the protests, so uncertainty about the turnout is the major obstacle. When mass media report about attendance, then the audience does not know the reasons for why did not others go. In social media these reasons can be revealed. For instance, [5] relates in his book that they put opinion polls online to find out why people do go to the protest and why not. The comments in Facebook help also to get insight into the decision-making of others. These comments also serve to raise spirits. Ghonim describes that he was surprised to see among the supporters persons that he did not expect to see. All this together help to "break the barrier of fear" ([5]) and allow individuals know that they are enough and together they can bring down the dictator.

\section{The model}

Suppose that there is a finite set of individuals, $N=\{1,2, \ldots, n\}$ and a dictator. Each individual chooses an action $a_{i} \in\{r, s\}$ where $r$ means "revolt" and $s$ "stay at home". We assume that each individual decides only once, and therefore

\footnotetext{
${ }^{1}$ In Egypt, members of Facebook events took photos of themselves and posted them as a way to confirm participation. Giving the face can be seen as a way to solve the commitment problem.
} 
decisions cannot be changed. Each person $i$ is either of type $\tau_{i}=w$ (willing to revolt) or $\tau_{i}=x$ (unwilling). Willing individuals are ready to participate in protests, unwilling individuals are reluctant to do so. We suppose that there is a fixed amount $\xi$ of individuals of the willing type, $\#\left\{i: \tau_{i}=w\right\}=\xi, \xi \in(0, n)$ and, therefore the number of unwilling citizens is also fixed, $\#\left\{i: \tau_{i}=x\right\}=$ $n-\xi .^{2} \quad$ We assume that $n$ and $\xi$ are common knowledge.

Individuals decide in a sequence. Let the type vector $\tau=\left(\tau_{1}, \tau_{2}, . ., \tau_{n}\right)$ denote the sequence of individuals. The set of sequences of length $n$ with $\xi$ willing citizens is given by

$$
\Upsilon^{n, \xi}=\left\{\tau: \#\left\{\tau_{j} \in \tau: \tau_{j}=w\right\}=\xi\right\} .
$$

There are $\left(\begin{array}{l}n \\ \xi\end{array}\right)$ possible type vectors and any of them is selected with equal probability.

The utility of each individual $i$ depends on her type and the actions chosen by all individuals. The amount of individuals participating in the revolution that is necessary to bring the revolt to triumph is given by the threshold $t$. Thus, the dictator is overthrown, if and only if at least $t$ citizens decide to revolt. Otherwise the dictator remains in power. Throughout the paper, it is assumed that $t \leq \xi$ is common knowledge, so there are always sufficient willing individuals in the society to change the regime and it is known by everyone. ${ }^{3}$ However, although the change is achieveable, it needs the coordinated action of individuals whose decision depends on the expected costs and benefits of participating in the revolution.

Let $a_{i}$ be the action chosen by individual $i$ and let $a=\left(a_{1}, a_{2}, . ., a_{n}\right)$ be the profile of actions. We assume that the utility of a willing individual isgiven as follows:

$$
\begin{array}{r}
u_{\mathrm{i}} * *\left(w, a: a_{\mathrm{i}}=r, \#\left\{a_{\mathrm{j}}: a_{\mathrm{j}}=r, j \in N\right\} \geq t\right)=u_{\mathrm{w}, \mathrm{r}, \mathrm{R}} \\
u_{\mathrm{i}} * *\left(w, a: a_{\mathrm{i}}=r, \#\left\{a_{\mathrm{j}}: a_{\mathrm{j}}=r, j \in N\right\}<t\right)=u_{\mathrm{w}, \mathrm{r}, \mathrm{F}} \\
u_{\mathrm{i}} * *\left(w, a: a_{\mathrm{i}}=s\right)=u_{\mathrm{w}, \mathrm{s}} \\
\text { with } u_{\mathrm{w}, \mathrm{r}, \mathrm{R}}>u_{\mathrm{w}, \mathrm{s}}>u_{\mathrm{w}, \mathrm{r}, \mathrm{F}}
\end{array}
$$

In words, willing individuals' utility is highest when they participate in a successful revolution $\left(u_{w, r, R}\right)$. In the utilities, the first subscript refers to the type of the individual, the second to the action that she undertakes, whereas the third one indicates the outcome. $R$ represents a successful revolution, while $F$ denotes that it has failed. If they stay at home, they derive less utility $\left(u_{w, s}\right) .{ }^{4}$ The lowest utility is derived from taking part in a revolution that is defeated.

\footnotetext{
${ }^{2}$ We use "individual" and "citizen" in an interchangeable manner.

and [8] use threshold models to study problems that involve collective action. [1] uses a threshold that is commonly known, as we do. In Edmond (2013) there is uncertainty about the threshold. In [2] each person has an individual threshold.

${ }^{4}$ The utility of staying at home may depend on whether the revolution triumphs or not. A successful revolt may bring better life to a willing individual who by staying at home avoids the
} 
The payoff $u_{w, r, F}$ can be interpreted as the punishment that the dictator imposes on protesters who participate in a revolution that fails. Suffering this punishment is the potential cost of participation. These utilities generate a game that resembles the classic stag-hunt situation. However, there are also unwilling individuals and their presence complicates the analysis.

With respect to unwilling individuals, we assume that they always prefer to stay at home:

$$
\begin{aligned}
u_{i}\left(x, a: a_{i}=s\right) & =u_{x, s} \\
u_{i}\left(x, a: a_{i}=r\right) & =u_{x, r} \\
u_{x, s} & >u_{x, r}
\end{aligned}
$$

For simplicity, unwilling individuals are all those individuals who would not participate in the revolt (whatever reasons they might have). Although their choice is always the same, their presence makes coordination difficult, since a willing individual who observes somebody staying at home does not know if it is due to an unwilling citizen or a willing one who decided not to participate in the revolt.

Notice that given these payoffs, the first best is achieved if the willing people coordinate and overthrow the dictator. The reason is that unwilling individuals' utility is not affected by the outcome of the revolt, whereas willing individuals are better off if the uprising is successful.

We suppose that the index of the individual $(i \in N)$ corresponds to her position in the sequence of decisions. The information about past decisions that is available to individuals depends on the communication technology. We consider three possibilities:

- No technology: Individuals do not have any information on previous choices when deciding.

- Mass media technology: The individuals have aggregate information about the actions that have been already taken. We model this fact by introducing into the information set of each individual the number of actions carried out by the predecessors. This represents a situation in which individuals obtain information through radio or television about the state of the revolution before making their decision and observe the aggregate turnout in the protests. We disregard manipulation of the mass media. ${ }^{5}$

- Social media technology: The individuals observe the individual action of each predecessor. This means that individual $i$ knows exactly which action

costs of the revolution. Thus, there may be free-riding issues at stake as well (see for instance [11]). Although these are interesting questions (and promising venues of future research), we disregard them and focus on the coordination problem embedded in the above payoffs.

${ }^{5}[4]$ argues that for example in Egypt a relatively free press could evolve (e.g. journal Al-Masry al-Yom, TV station Dream) and Al-Jazeera, a media outlet with a high standard also broadcasts in many Arab countries. Thus, in principle citizens could have a more or less accurate view of the situation. 
was chosen by each of its $i-1$ predecessors. When deciding whether to participate in the revolution, through Facebook or Twitter (or any other social media) the individual observes the exact history of previous decisions.

Let $\varphi_{i}$ denote the information set of individual $i$. When no communication technology is available, then $\varphi_{i}=\left\{\tau_{i}\right\}$. Thus, in this case individuals only know their own types, but nothing about other individuals' decisions. Mass media technology implies $\varphi_{i}=\left\{\tau_{i}, \rho_{i}, i-\rho_{i}-1\right\}$ where $\rho_{i}$ represents the number of individuals who have decided to revolt up to individual $i$ ( $\rho_{i}=\#\left\{a_{j}=\right.$ $r, j<i\})$. Thus, we assume that under mass media individuals know both the amount of predecessors who decided to participate and who chose to stay at home. It is plausible if citizens may infer somehow how many individuals have already decided, that is they may figure out their position in the sequence of decisions. The information set under the social media technology becomes $\varphi_{i}=\left\{\tau_{i},\left\{a_{j}, \forall j<i\right\}\right\}$, so each previous decision is observed, ordered according to the position. ${ }^{6}$ As already claimed, on Twitter and Facebook the exact history of past events can be followed, so eventually really a lot of past decisions can be observed. Even so, our assumptions are demanding: it is hard to believe that through TV an individual is able to know exactly how many other individuals have joined the revolution and on Facebook not all previous actions are observable, since not everybody uses Facebook or is member of a special Facebook-group. To derive clean theoretical results, we decided to use these extreme assumptions. We believe that in spite of our strong assumptions we capture an essential difference between mass and social media in the form of how disaggregated the information is.

When no communication technology exists, the lack of information generates a simultaneous-move game. For the other two cases we specify the extent to which previous decisions are observable through the communication technologies. When defining the information sets, we assumed implicitly that if a communication technology is available to the society, then individuals are completely informed. As a consequence, individuals may infer perfectly their position in the sequence of decisions. Mass and social media report about all previous decisions: mass media aggregate the information whereas social media present it in a disaggregated form. Our modeling choice allows us to study in a clear way the difference in the effects that mass and social media have on the evolution of revolts. ${ }^{7}$

Our aim is to determine how the different types of communication technology (or the absence of it) affect the outcome of revolutions. Moving from no technology towards social media the amount of available information increases.

\footnotetext{
${ }^{6}[11],[12]$ and [13] addresses questions of information aggregation and political action. In her models, individuals observe each previous action, but she does not study how different communication technologies affect coordination.

${ }^{7}$ Arguably, it is unlikely that a society is completely informed about the state of the revolution. A more realistic model would have people receiving partial aggregate information, some particular information about the decisions of the personal contacts, and no information about decisions of some others in the society. We leave this issue for future research.
} 
In principle, the effect of more information is ambiguous: more information may be good for revolution since it allows a better signaling of own actions to the subsequent individuals; but at the same time, it could also foster coordination failure, e.g. if individuals find out that too many of their predecessors have chosen not to participate in the revolution. Note that they may observe many individuals staying at home because those observed citizens were the unwilling ones.

\subsection{Revolutions under different information structures}

Given our environment, revolution is the socially efficient outcome. However, when information about other individuals is not available, this efficient outcome may fail to materialize as shown by our first result.

Proposition 1 If no communication technology is available in the society, there are multiple equilibria.

This result is a straightforward consequence of the assumptions on the utilities, that imply the existence of multiple equilibria in the simultaneous case. Since $u_{w, r, R}>u_{w, s}>u_{w, r, F}$, for the willing individuals it is optimal to participate if the otherwilling individuals are participating, while it is optimal to stay at home if nobody else is participating. If a willing individual believes that the other willing individuals will participate in the revolution, then she best responds to this belief by participating as well. However, if they hold the opposite beliefs, then staying at home is the best response. In fact, there are two symmetric equilibria in pure strategies: i) all willing individuals participate in the revolution; ii) no willing individual goes to the streets.

The previous result does not depend on whether type is a public information or not. However, when a communication technology is available this distinction becomes relevant as shown next.

\section{Type is public information}

It is instructive to see how the existence of information affects the outcome of revolts in a perfect information setup in which the willingness to revolt (that is, the type of individuals) is transmitted by the communication technology. This can be the case, for instance, when the people willing to overthrow the dictator belong to the same social group (e.g. religious association, ethnic groups or social classes), so that the individual knows the type of the people who have decided previously. For example, in Egypt the youth in general was unsatisfied with the regime, and so were also the Copts. We model this situation by introducing the type of the predecessors in the information available to each individual.

In the case of mass media the information set of individual $i$ includes also the amount of willing individuals up to (but excluding) individual $i$, denoted as $\xi_{i}$. Thus, the information set becomes $\varphi_{i}=\left\{\tau_{i}, \rho_{i}, i-\rho_{i}-1, \xi_{i}\right\}$. Given this information set, individual $i$ knows the amount of willing individuals that precede 
her and how many decided to stay at home. This is a valuable information since it also reveals how many willing individuals are left to decide. For instance, if there were many willing individuals who abstained from participating in the protests, then it is more probable that the total number of protesters will fall short of the threshold, so staying at home may be a best response. Regarding social media, the assumption about publicly observed types implies that the information set of individual $i$ becomes $\varphi_{i}=\left\{\tau_{i},\left\{a_{j}, \forall j<i\right\},\left\{\tau_{j}, \forall j<i\right\}\right\}$. Hence, both the type and decision of each preceding individual are observed.

Individual $i$ 's strategy is conditioned on the information set. It is defined as $\boldsymbol{\sigma}_{i}: \varphi_{i} \rightarrow\{r, s\}$. Let $\boldsymbol{\sigma} \in \boldsymbol{\Sigma}$ be a strategy profile, that is, $\boldsymbol{\sigma}=\left(\boldsymbol{\sigma}_{1}, \ldots, \boldsymbol{\sigma}_{n}\right)$. Let $h_{i}$ bethe history of the game up to $i$, formed by a type vector and a sequence of decision, $h_{i}=\left\{a_{1}, \ldots, a_{i-1}\right\}$.

We find that given a type vector the unique subgame perfect equilibrium with the two communication technologies is that the revolution succeeds, and every willing individual chooses to revolt. In this case, both technologies generate the same equilibrium.

Proposition 2 If type is public information, every willing individual revolts in any subgame perfect equilibrium under both communication technologies.

Proof See Appendix A.

The proof of the result makes use of a backward induction argument. A willing individual chooses to join the revolution if she observes that already $t-1$ individuals have revolted. Given this fact, a willing individual who observes $t-2$ people participating in the revolution decides to revolt if she knows that after her there is at least one more willing individual. Since predecessors' types are publicly observable, she can infer if there is a willing individual behind her. Iterating this reasoning, a willing individual decides to revolt when up to her sufficient willing individuals have chosen to do so and she anticipates that enough willing citizens behind her will follow suit. The conditions ensuring that this requirement is met at any position imply that all willing citizens choose to participate in the revolution.

Our assumption on predecessors' type being public information is plausible in environments where the people willing to overthrow the dictator can be associated to particular groups. Under these circumstances, it is likely that when individuals acquire information, they know both the actions and the types of those who have already decided. In this case, the existence of any of the communication technologies ensures that the revolution triumphs in our simplified environment. If there is no technology, it is possible to find equilibria where the individuals do not coordinate and the dictator remains in power. This result suggests that given the lack of uncertainty about types social media has no additional value over mass media, both lead to successful coordination. As claimed earlier, the uncertainty about how many individuals would participate in a revolution is the main barrier and it makes most of the individuals who are discontented to stay at home. This uncertainty comes - at least partly - from the uncertainty about types that we consider next. 


\section{Type is private information}

We study now the case where type is private information, although $\xi$ is common knowledge. That is, individuals know that there are sufficient people willing to revolt and overthrow the dictator, but they do not know who they are. Given the untrust and fear generated by dictators in repressive regimes, this setup may appear more plausible. As argued by several authors (e.g. [6], [9], [10]), decision making in any revolution is clouded by a considerable amount of uncertainty. This uncertainty blurs the information about the public discontent due to several reasons, e.g. the lack of free press, falsified preference revelation to official public opinion polls or the presence of informants penetrating all layers of the society, among others.

When type is private information, communication technologies only transmit to individuals the actions of predecessors. For the mass media technology, the information set of individual $i$ becomes $\varphi_{i}=\left\{\tau_{i}, \rho_{i}, i-\rho_{i}-1\right\}$, so the amount of citizens of each type who have already decided is not known. In the case of social media, citizen $i$ 's information set is given by $\varphi_{i}=\left\{\tau_{i},\left\{a_{j}, \forall j<i\right\}\right\}$. Hence, citizen $i$ cannot distinguish perfectly the type of her predecessors although she knows the exact sequence of decisions. Remember that observing that somebody revolts indicates unambigously that she is of the willing type, since unwilling citizens always stay at home. However, since willing individuals may choose to stay at home, observing that someone has chosen not to participate in the revolt does not imply that she is unwilling.

Since type cannot be observed, we look for Perfect Bayesian equilibria. The following proposition shows that under such circumstances the sort of communication technology matters. With mass media the revolution succeeds only when certain conditions are met.

Proposition 3 Consider the case where type is private information. Under the social media technology, the revolution always succeeds because each willing individual revolts in any Perfect Bayesian equilibrium. Under the mass media technology,

- if $t<\left[\frac{n}{n-\xi+1}\right]+1$, each willing individual revolts and the revolution succeeds;

- if $t \geq\left[\frac{n}{n-\xi+1}\right]+1$, there are equilibria where the revolution is unsuccessful and nobody revolts for certain values of $u_{w, r, R} ; u_{w, s}$ and $u_{w, r, F}$,

where $[x]$ is the integer part of $x$.

The logic behind social media part of the proposition is that if a willing individual faces a certain set of histories, then she can be sure that all subsequent willing individuals will revolt. An example is the history that consists of $t-1$ revolts. Consider histories that are identical to those in the previous set of histories except for a "revolt" that is missing from the end of them (e.g. a history made up of $t-2$ revolts). Given these histories, a willing individual 
would revolt in order to generate a history that ensures that all subsequent willing citizens revolt and the revolution triumphs. Hence, when observing that an individual facing such a history does not revolt, then individuals infer that she is unwilling. Then, a willing individual knows that there are enough willing individuals left to decide and by revolting she can convince them to revolt as well.

Under mass media such "identification of types" is not possible. There, given a number of previous revolts a willing individual will revolt only if she knows that there are sufficient willing citizens behind and enough of them will revolt. Thus, for instance a willing individual can only be sure that there is at least one more willing citizen after her if there at least $n-\xi+1$ individuals left. That is, if the number of citizens who have not decided yet is higher than the number of unwilling citizens. To make sure that more than one (say two) subsequent willing individuals revolt imposes additional restrictions: the first of those willing individuals must be sure that there is at least one more willing individual behind her. These considerations are embedded in the second part of proposition 3.

Proposition 3 states that social media technology enables revolution with certainty, when people know that there are sufficient other people willing to take part in the revolt, even if they do not know who they are. Mass media bring a revolution to triumph only if the required number of participants to succeed is sufficiently low. Mass media do not ensure that the revolution wins if a relatively high proportion of the society is required to participate. The main difference is that social media allow to identify if individuals who have chosen to stay at home were unwilling or not. Hence, it is possible to infer exactly how many willing individuals have not decided yet and by backward induction their choices can be anticipated. These elements ensure that all willing individuals revolt. By contrast, when only mass media are available, inferring the type of previous individuals who stayed at home is generally not possible. As a consequence, it is considerably more difficult to make sure that there are enough willing individuals left in the sequence of decisions and that those individuals will revolt. Hence, with mass media the condition for successful revolts becomes quite demanding.

\section{Examples}

We illustrate our results of the previous section with unobservable types with two examples. In the first one we analyze a simple society of $n=4$ individuals in order to clarify the mechanism why social media promote revolutions more than mass media. In the second example, we use a society of $n=10$ in order to illustrate the quantitative difference in the effectiveness of social media versus mass media in fostering revolutions. 


\subsection{Example 1}

Imagine a society of four individuals, three of them are willing to overthrow the dictator. The revolution is successful if at least three individuals participate $(n=4, \xi=3, t=3)$. As before, payoffs are such that $u_{w, r, R}>u_{w, s}>u_{w, r, F}$. In Figure 1 we illustrate the differences between the communication technologies.

We have drawn a reduced extensive-form representation of the game generated by each communication technology. We name it reduced form because we have simplified the representation drawing only one of the four branches that would follow each of the type vectors. At the beginning of the game, nature selects at random one of them. In the four possible type vectors willing citizens are represented by black circles and the unwilling one by a white circle. Since individuals only observe actions but not types, we have drawn individuals as grey circles in the rest of the tree. In Appendix $\mathrm{C}$ we represent the complete decision tree for the social media case.

At the top, we represent the case without communication technology in which the individuals decide without knowing the decisions of their predecessors. Thus, they only know the position, but nothing else. All nodes at a given position belong to the same information set. In the middle, we depict the case of mass media. In this case, an individual only knows the number of citizens that already joined the protests. For instance, imagine that the fourth individual is informed that two individuals have chosen to revolt (and, consequently, one stayed at home). She is not able to distinguish if the sequence was $(r, r, s)$, $(r, s, r)$ or $(s, r, r)$, hence the information that the citizen in position 4 has is compatible with three possible sequences of decisions. In contrast to the previous case, here the nodes at a given position are partitioned in different information sets. At the bottom, we draw the social media case. Individuals are able to identify perfectly the sequence of decisions (the information sets are singletons), but they do not know the type vector (even though through observed actions they may infer something about it). We show that in the case of no communication technology and mass media we may find equilibria leading to both successful revolution and to everyone staying at home. By contrast, with social media the unique equilibrium is the one where all willing individuals revolt.

Without communication technology, there are two possible equilibria (in pure strategies): the three willing individuals either choose to revolt or choose to stay at home. This is the case because for a willing individual to revolt (stay at home) is the best response when the other willing individuals choose to revolt (stay at home).

Next, consider the case with communication. From now on, we focus on a willing individual's decision. Note that in the information sets where $\rho_{3}=2$ or $\rho_{4}=2$ (the willing observes 2 previous revolts either in position 3 or 4 ), the best response is to revolt. Given this fact, in an information set where $\rho_{2}=1$ for any possible belief the best response is also to revolt: the willing individual knows that she will be followed by at least 1 willing who will revolt. In information sets where $\rho_{4} \in\{0,1\}$ or $\rho_{3}=0$ the revolution is doomed to fail and best response 
is to stay at home.
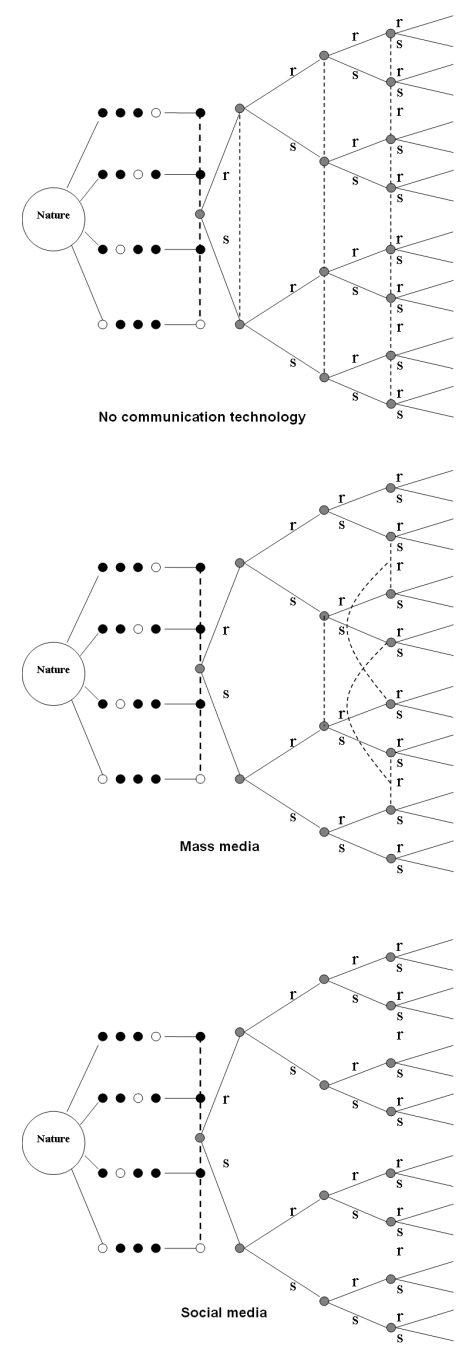

Figure 1. Reduced extensive-form representation

Thus, when communication is in place, we are left with the information sets with $\rho_{1} ; \rho_{2}=0$ and $\rho_{3}=1$. In words, we do not know yet what a willing citizen does when she is the first to decide; when she is in the second position and observes no protester and when third in the sequence of decision and observes one protester.

We show now that for given payoffs, with mass media there are multiplicity of equilibria including one of unsuccessful revolution, while it is not the case with social media, where the revolution always succeeds in equilibrium. 
Let us focus on the information sets where $\rho_{3}=1$. In case of mass media, the citizen knows that before her an individual joined the protests, while another one stayed at home. With social media, the citizen would know the concrete sequence of decision, $\{\mathrm{r}, \mathrm{s}\}$ or $\{\mathrm{s}, \mathrm{r}\}$. This difference is crucial for coordination. We show first the no-revolution equilibrium for the case of mass media. Consider the strategy of staying at home in the information sets where $\rho_{1} ; \rho_{2}=0$ and $\rho_{3}=1$, and suppose that at the other information sets the individual acts as established before. We show that then it may be optimal to stay at home when $\rho_{3}=1$. This is an information set off the equilibrium path. We construct now some reasonable beliefs about the type of the predecessors. The two possible histories are $\{\mathrm{r}, \mathrm{s}\}$ or $\{\mathrm{s}, \mathrm{r}\}$. The first of them, $\{\mathrm{r}, \mathrm{s}\}$, implies the deviation of the first individual from the proposed strategy profile, and given that a willing revolts when $\rho_{2}=1$, the second citizen is an unwilling one. The second history, $\{\mathrm{s}, \mathrm{r}\}$, implies that the second individual (willing or unwilling) deviated from the proposed strategy. Thus, a reasonable belief for this off-equilibrium information set would be that previous actions correspond to:

- First citizen willing, second unwilling, who chose $\{\mathrm{r}, \mathrm{s}\}$

- First citizen willing, second unwilling, who chose $\{\mathrm{s}, \mathrm{r}\}$

- Two willing ones, who chose $\{\mathrm{s}, \mathrm{r}\}$.

Note that any of those histories includes only one deviation from the proposed strategies (stay at home if $\rho_{1}$ or $\rho_{2}=0$ but revolt if $\rho_{2}=1$ ). Thus a reasonable belief would assign, for instance, probability of $1 / 3$ to any of them. If it is the case, then in the information set where $\rho_{3}=1$, there is a probability of $1 / 3$ of being preceded by the two willings; in that case, the revolution is doomed to fail with probability $1 / 3$ and it will triumph with probability $2 / 3$ (if the willing citizen in $\rho_{3}=1$ revolts and another willing decides after her). For a punishment sufficiently strong in the case of a failed revolution, the expected utility of a citizen becomes negative, so the citizen prefers to stay at home. ${ }^{8}$

This equilibrium of no revolution is not possible under social media. In this case, when a citizen in the third position observes a revolt, she can distinguish if the sequence is $\{\mathrm{r}, \mathrm{s}\}$ or $\{\mathrm{s}, \mathrm{r}\}$. In the former case the citizen believes with probability 1 that the individual who stayed at home is the unwilling (a willing citizen would revolt if she had observed the previous revolt). Therefore, with probability 1 the last citizen to decide is a willing one, and the best response in the information set with $\{\mathrm{r}, \mathrm{s}\}$ is to revolt. As a consequence, the best response when being the first to decide is to revolt, since by previous arguments any history starting with a revolt ends up in a successful revolution. As a consequence, in the information set $\{\mathrm{s}\}$, that is when observing that the first individual has stayed at home, willing citizens know that she must have been the unwilling one. Thus, the type vector is $(x, w, w, w)$ and by backward induction they play

\footnotetext{
${ }^{8}$ It is easy to verify the optimality of staying at home for the cases in which the information set includes $\rho_{1}$ and $\rho_{2}=0$. It is also easy to verify that to revolt in $\rho_{1}, \rho_{2}=0$ and $\rho_{3}=1$ implies an equilibrium in which the revolution triumphs.
} 
the unique equilibrium of this subgame in which all of them rebel against the dictator. Since the willing individual in position 4 (3) revolts when observing two (one) previous revolts, the willing citizen in position 2 will revolt and thus the revolution triumphs. Hence, as the game unfolds in any information set that can be reached $(\emptyset,(r),(s),(r, s),(s, r)$ and those with two revolts and one staying at home), willing individuals revolt and the dictator is overthrown. Notice that these arguments are valid for any payoffs such that $u_{w, r, R}>u_{w, s}>u_{w, r, F}$.

Thus, we have illustrated why equilibrium is unique with social media and how multiple equilibria may arise under mass media. Proposition 4 generalizes the main insights of this example. We turn now to show under what conditions unique outcome with all willing citizens revolting can be achieved with mass media.

\subsection{Example 2}

Mass media can also foment revolutions, for any possible payoffs, but only if just a relatively low proportion of the society is required to participate in order to triumph. Imagine a society of 10 individuals, where 7 of them want to overthrow the dictator that is achieved if at least 5 citizens revolt $(n=10, \xi=7)$. If all individuals decide simultaneously (the case without communication technology), both results are possible: the revolution may succeed or fail. This occurs both when type is public or private information. If type is public information, following Proposition 2 the unique equilibrium implies that revolution occurs for sure with either sort of communication technology.

Suppose that type is private information: it is unknown which concrete people are in favour of the revolution, although every individual knows that there are 7 people willing to revolt. Because of Proposition 3, under mass media technology, for given payoffs, it is possible that nobody takes part in the revolts, for any $t>3=\left[\frac{n}{n-\xi+1}\right]+1$. This means that even though more than two-thirds of the citizens wish to overthrow the dictator, they succeed for sure only if 3 or less people are required to participate in the revolts. ${ }^{9}$

The intuition behind this result is the following. If an individual can be sure that the revolution succeeds, then she joins the protests. Whenever she may believe that with positive probability the revolution fails, it is possible to find a punishment that is sufficiently large to deter individuals from participating in the protests. A willing individual at position $[7,10]$ cannot be sure that among the subsequent citizens there is a willing one, since possibly all of them are unwilling. Hence, if she revolts, in the worst case the number of revolts increases only by 1 . Thus, a willing individual at these positions revolts if she observes $t-1$ previous revolts. That is, she revolts if only one more revolting individual is needed to bring the uprising to triumph. At position 6 , a willing individual knows that there is for sure one more willing individual behind her and she can

\footnotetext{
${ }^{9}$ The difference becomes larger if we scale up the numbers. If $n=100, \xi=70$ and $t=50$, then the revolution succeeds if only 4 or less individuals are required to join the protest in order to triumph.
} 
convince her to revolt with certainty if she will observe $t-1$ revolts. Thus, the willing citizen at position 6 revolts if she observes $t-2$ revolts. A willing individual at position 5 knows that there are at least two willing citizens behind her, but she cannot make sure that both of them will revolt if she decides to revolt. This is the case because possibly the first of the willing individuals is at position 9 and then by previous arguments this citizen cannot be sure that there is another willing individual behind her. Hence, a willing citizen at position 5 knows that by revolting she can prompt for sure one more willing individual to participate, so she revolts if she observes $t-2$ revolts. The same reasoning applies to willing individuals at position 4 and 3 . A willing individual at position 2 knows that there are at least 5 willing individuals behind her. In the worst case, the next one is at position 6 and by previous reasoning even she knows that there is one more willing citizen behind her. So, at position 2 a willing individual knows that she can induce two more willing citizens. Hence, if she observes that $t-3$ individuals have already revolted, then she joins the protest. The same is true for a willing individual at position 1 . Note that a willing individual at position 1 cannot observe anybody revolting, so the threshold that enables a succesful revolution is 3 or less citizens. Probably, the unwilling individuals are at the first 3 positions. However, rational actors understanding the game infer that, if with a threshold of 3 none of the first 2 citizens revolted, then it must be due to the fact that those individuals were unwilling. But it reveals at the same time, that there are enough willing individuals behind, so a willing individual at position 3 (or 4) will revolt. Note that with a threshold of 3 (or less) all willing individuals will revolt by the previous arguments.

With higher thresholds, the revolution may fail. In particular, suppose that payoffs are $u_{w, r, R}=1, u_{w, s}=0, u_{w, r, F}=-10^{100}$ and $t=4$. Hence, the dictator would punish very strongly (say, execute) the participants of a failed revolution. Consider the following strategy for willing individuals

$$
\bar{\sigma}_{i}\left(\varphi_{i}\right)=\left\{\begin{array}{c}
\rho_{i}=3, \forall i \\
\rho_{i}=2, \forall i \leq 6 \\
\rho_{i}=1, \forall i \leq 2 \\
\text { sotherwise }
\end{array}\right.
$$

where $\rho_{i}$ is the amount of participants that have chosen $r$ before individual i. A willing individual revolts at the information sets specified above. We have to prove that the strategy is optimal in the rest of information sets. Consider first the case of a willing citizen at position 1. Obviously, she observes zero revolts, so by the proposed strategy profile she should stay at home. What if she deviates? Conditional on the first individual being willing, the probability that the second citizen is willing too is $\frac{6}{9}$ (since all sequences of decision are equiprobable). Thus, with probability $\frac{2}{3}$ the deviation is successful and if the subsequent citizens follow the above strategy, then the revolution triumphs. However, with probability $\frac{1}{3}$ the next citizen is unwilling and she will stay at home. Then, if the subsequent willing individuals act according to the proposed strategy, the revolution fails. Given the payoffs it is easy to calculate that the expected utility of a willing individual in position 1 is negative, so the deviation 
is not profitable. The same argument can be applied for the rest of information sets to show that no deviation is profitable.

In our example, mass media communication guarantees that the revolt succeeds only if $t \leq 3$ individuals' participation is necessary to overthrow the dictator. To get an idea how our results affect mobilization, we scale up the numbers. In a society of 100 individuals in which 51 people are required to participate in the protests to change the regime, mass media facilitate a successful revolution (with all willing individuals revolting) for any payoffs only if it is known that all individuals $(\xi=100)$ are in favour of the revolution. If the required threshold were $t=49$, mass media would guarantee that the revolution succeeds only if it was commonly known that at least $\xi=99$ individuals are of the willing type. Thus, mass media lead to a successful revolution only if there is a huge amount of people willing to participate in the protests, or if the dictator is very weak (the threshold is very low). In any other case, the dictator could implement a sufficiently high punishment $\left(u_{w, r, F}\right)$ so that revolts may not occur in equilibrium. By contrast, social media would guarantee the coordination in the revolution outcome with much less demanding conditions.

\section{Conclusion}

In this paper we have studied the differential effect of communication technologies on the outcome of revolutions. We distinguish mass and social media by the degree of information that they provide. In particular, mass media supply an aggregate piece of information about the actual state of revolution, while when informed through social media individuals know the precise sequence of decisions that led to the actual state.

When individuals' types are public information, both communication technologies enable a successful revolution with certainty, a result that does not hold without communication technology. Hence, both mass and social media facilitate the overthrow of the dictator. When types are private information, we show that the sort of communication technology is relevant: with social media the revolution succeeds in the unique equilibrium. However, with mass media the revolution may fail except in cases when the amount of people required to succeed is sufficiently low. If the punishment for participating in a failed revolution is sufficiently high, with mass media the no-revolution equilibrium may be sustained, but it is not true for the social media technology. In this sense, we argue that social media facilitate revolts more than mass media do.

As argued earlier, we leave aside important issues (e.g. manipulation of information) and our model relies on strong simplifications (for instance, complete information about previous decisions). It is not easy to see how these omitted elements affect mass and social media. If the distortions and biases that these factors cause are not specific to only one of the media technologies, but the effects are more or less uniform across them, then our model can at least partly explain some of the differences that communication through social media is bringing to the society. Our results suggest that social media facilitate the 
efficient decisions under payoff structures that possibly generate coordination failures under mass media.

\section{Aknowledgments}

The authors kindly acknowledge financial support from the Spanish Ministry of Science and Innovation under the projects ECO2008-00510 (Hubert Janos Kiss) and ECO2010-19830 (Alfonso Rosa-García). Kiss is also grateful for financial support from the Hungarian Scientific Research Fund (OTKA) under the project PD 105934.

\section{References}

[1] De Mesquita, Ethan Bueno. "Regime change and revolutionary entrepreneurs." American Political Science Review 104.3 (2010): 446-466.

[2] Chwe, M., 2000. Communication and coordination in social networks. The Review of Economic Studies, 67, 1-16

[3] Edmond, Chris. Information manipulation, coordination and regime change. The Review of Economic Studies, forthcoming

[4] Filiu, Jean-Pierre. The Arab revolution: ten lessons from the democratic uprising. Oxford University Press, 2011.

[5] Ghonim, Wael. Revolution 2.0: The Power of the People Is Greater Than the People in Power-A Memoir. Mariner Books, 2012.

[6] Ginkel, J., A. Smith, 1999 'So You Say You Want a Revolution: A Game Theoretic Explanation of Revolution in Repressive Regimes', Journal of Conflict Resolution, Vol. 43 No. 3 (June 1999), 291-316

[7] Goldstone, Jack. "Toward a fourth generation of revolutionary theory." Annual Review of Political Science 4 (2001): 139-187.

[8] Granovetter, M. (1978) "Threshold Models of Collective Behavior", The American Journal of Sociology 83, 1420-1443

[9] Kuran, T. (1991), 'Now out of never: the element of surprise in the East European revolution of 1989', World Politics, Vol. 44, 7-48

[10] Kuran, T. (1995) 'Private truths, public lies: The social consequences of preference falsification', Cambridge, MA, Harvard University Press

[11] Lohmann, S. (1993) 'A Signaling Model of Informative and Manipulative Political Action', The American Political Science Review, Vol. 87, No. 2 (Jun., 1993), 319-333 
[12] Lohmann, S. (1994a) 'Information Aggregation Through Costly Political Action', The American Economic Review, Vol. 84, No. 3 (Jun., 1994), 518530

[13] Lohmann, S. (1994b) 'The Dynamics of Informational Cascades: The Monday Demonstrations in Leipzig, East Germany, 1989-91', World Politics, Vol. 47, No. 1 (Oct., 1994), 42-101

[14] Passy Florence, Social Networks Matter. But How ? In: Diani Mario, McAdam Doug (eds.) Social Movements and Networks. Relational Approaches to Collective Action. University Press, Oxford, pp. 21-48, 2003.

[15] Schelling, T. C. (1978), "Micromotives and macrobehavior", New York: W. W. Norton

\section{Appendix A}

Proposition 2 If type is public information, every willing individual revolts in any subgame perfect equilibrium under both communication technologies.

Proof The existence of the equilibrium is guaranteed by standard arguments. We show that in the unique subgame perfect equilibrium each willing individual revolts.

Let us define $\alpha_{i}=\#\left\{\tau_{j}=w: j \leq i \mid \tau_{i}=w, \tau\right\}$, that is the position of a willing individual $i$ among the willing individuals in a given type vector $(\tau)$. Note that $\alpha_{i} \in\{1,2, . . \xi\}$, with $\xi>t$ and since type is public information $\alpha_{i}$ is in fact observable.

By backward induction, the last willing individual $\left(\alpha_{i}=\xi\right)$ revolts if at least $t-1$ other willing individuals decided to revolt, because if she follows suit, then the number of protesters reaches the threshold $t$, so the revolution will be successful. Otherwise she decides to stay at home. The next to the last willing individual $\left(\alpha_{i}=\xi-1\right)$ revolts if at least $t-2$ willing predecessors chose to revolt anticipating that then also the last willing individual will join in. Again, if the condition is not met, then she stays at home. This argument can be repeated for all willing individuals: the individual $\alpha_{i}$ revolts if at least $t-\left(\xi-\alpha_{i}+1\right)$ other individuals decided to revolt, otherwise she prefers to stay at home. As a consequence, the first willing individual $\left(\alpha_{i}=1\right)$ revolts even if she does not observe anybody revolting $(t-\xi<0)$. Therefore, the revolution succeeds.

Notice that the previous argument to find the unique subgame perfect equilibrium works for both types of media, thus Proposition 2 holds.

\section{Appendix B}

Proposition 4 Consider the case where type is private information. Under the social media technology, the revolution always succeeds because each willing individual revolts in any Perfect Bayesian equilibrium. Under the mass media technology, 
- if $t<\left[\frac{n}{n-\xi+1}\right]+1$, each willing individual revolts and the revolution succeeds;

- if $t \geq\left[\frac{n}{n-\xi+1}\right]+1$, there are equilibria where the revolution is unsuccessful and nobody revolts for certain values of $u_{w, r, R} ; u_{w, s}$ and $u_{w, r, F}$,

where $[x]$ is the integer part of $x$.

Proof Social media

Denote by $H^{t r}(k)$ the set of truthful histories which contain $k$ revolts (and any $\lambda \in[0, n-\xi] s$-s) at any position $i \geq k .{ }^{10} \quad$ Truthful histories are those for which actions reveal the type, so anyone can make sure that only unwilling citizens stayed at home and the willing ones revolted. Since only willing individuals revolt, but both willing and unwilling may stay at home, a history is not truthful if one of the "staying at home" is due to a willing citizen. We can make sure that a history is truthful if when observing an $s$ we can show that a willing individual observing a history that precedes the $s$ in question would have revolted instead of staying at home (that is that staying at home is dominated for her).

Definition 1 A history $h_{i}$ at position $i$ is truthful, if and only if for any $a_{j}=s$, $j<i$ we have that $\sigma_{j}\left(\tau_{j}=w, h_{j-1}\right)=s$ is a strictly dominated strategy.

That is, if there is an (or more) $s$ in a truthful history, then we have that a willing individual having observed the history leading up to that $s$ would have revolted instead of staying at home. Note that when facing a truthful history, a willing individual knows the exact distribution of possible continuation type vectors. Important for our analysis, she knows how many willing individuals are behind. Henceforth, acting truthfully at any information set means, that an unwilling individual stays at home, whereas a willing one revolts.

Lemma 1 Assume that once an element in $H^{\text {tr }}(k \geq \hat{k})$ is reached all subsequent willing individuals will revolt, that is, $\sigma_{j}\left(\tau_{j}=w, h^{t r}(k \geq \hat{k})\right)=r$. Then, for the set of truthful histories which contain $\hat{k}-1$ revolts and any $\lambda \in[0, n-\xi]$ "stayings at home", we have $\sigma_{j}\left(\tau_{j}=w, h^{\operatorname{tr}}(\hat{k}-1)\right)=r$.

Proof The lemma assumes that once a truthful history containing $\hat{k}$ revolts and at most $n-\xi$ "stayings at home" is reached, for any possible continuation vector subsequent willing individuals will revolt. Therefore, the only equilibrium strategy when observing a truthful history with $\hat{k}-1$ revolts is to revolt if willing. If a willing individual observes $h^{\text {tr }}(\hat{k}-1) \in H^{\operatorname{tr}}(\hat{k}-1)$, then by revolting she generates a history which belongs to $H^{\text {tr }}(\hat{k})$. By our assumption, all subsequent willing citizens will revolt, so the revolution triumphs. Given such a history the unique perfect Bayesian equilibrium strategy is to be truthful, since there is no unilateral profitable deviation.

${ }^{10}$ Clearly, any history with more than $n-\xi$ "stayings at home" cannot be truthful. 
It is obvious that if a willing individual observes an element in $H^{t r}(x)$ where $x \geq t-1$, then she will revolt and the revolution triumphs. As a consequence, by lemma (1) if a willing individual observes an element in $H^{t r}(t-2)$, then she will revolt and again the dictator is ushered from power. Note that any history beginning with $t-1$ revolts belongs to $H^{t r}(t-1)$. Any $s$ after $t-1$ revolts is due to unwilling individuals, since for a willing citizen staying at home is strictly dominated in this case. Notice also that any history starting with $t-2$ revolts is also a truthful history and any willing individual when observing any history that begins with $t-2$ revolts would revolt as well. This is the case for the following reasons. Clearly, $\sigma_{t-1}\left(\tau_{j}=w, h^{t r}(t-2)\right)=r$, that is a willing individual at position $t-1$, who observes $t-2$ revolts joins the protest, because then subsequent individuals would observe a history starting with $t-1$ revolts and a willing individual at any subsequent position would revolt. Thus, for this willing individual staying at home is a dominated strategy. As a consequence, if $a_{t-1}=s$, that is citizen $t-1$ stays at home, then it must be an unwilling individual. Thus, the history that starts with $t-2$ revolts and is followed by an $s$ is a truthful history. By lemma (1) a willing individual at position $t$ facing this history which is an element in $H^{t r}(t-2)$ would revolt, so $\sigma_{t}\left(\tau_{j}=w, h^{t r}(t-2)\right)=r$. By the same reason, a willing individual at position $t+1$ observing $t-2$ revolts followed by two $s$-s would revolt, since she would cause a truthful history belonging to $H^{\operatorname{tr}}(t-1)$ and that would lead to successful revolution. Applying the same reasoning leads to the conclusion that when a willing individual observes any history that starts with $t-2$ revolts and has at most $n-\xi$ "stayings at home", she will join the revolution. We have shown in this paragraph that a willing citizen facing any history that belongs to $H^{t r}(t-2)$ would revolt, since by backward induction all subsequent willing individuals would participate in the uprising. And we have also shown that all histories that start with $t-2$ revolts and have at most $n-\xi$ "stayings at home" are truthful histories, implying that willing individuals revolt in these cases.

The previous argument can be repeated. By lemma (1) if a willing individual observes an element in $H^{t r}(t-3)$, then she will revolt producing a history that belongs to $H^{t r}(t-2)$ and as a consequence all subsequent willing individuals revolt. It is also true by the previous arguments that any history that starts with $t-3$ revolts and has at most $n-\xi$ "stayings at home" is a truthful history, so willing individuals observing these histories will revolt.

When applying the previous line of reasoning iteratively, we get that any history starting with $0,1,2 \ldots \xi-1$ revolts and that have at most $n-\xi$ "stayings at home" afterwards are truthful histories and willing individuals facing these histories revolt, because through the previous reasoning we have eliminated iteratively the dominated strategy of staying at home for those histories. We summarize these insights in the following corollary.

Corollary 1 Assume that once an element in $H^{t r}(k \geq t-1)$ is reached all subsequent willing individuals will revolt, that is, $\sigma_{j}\left(\tau_{j}=w, h^{t r}(k \geq \hat{k})\right)=r$. Then, for the set of truthful histories which contain $[0, t-1]$ revolts and any $\lambda \in[0, n-\xi]$ "stayings at home", we have $\sigma_{j}\left(\tau_{j}=w, h^{\operatorname{tr}}(\hat{k}-1)\right)=r$. 
Note that we have not covered all the possible histories. Concretely, we have not dealt with histories that contain more than $n-\xi$ "stayings at home". These are histories that reveal that there is at least one willing individual who has stayed at home. Given some of these histories revolting may be the optimal decision. However, we assume the worst scenario: at those histories willing individuals stay at home. This is the the most hostile assumption that goes against revolution. However, the set of histories that we analyzed and for that we know how willing individuals decide is enough to see what may happen in the game as it unfolds. If the first individual is willing, then she faces a truthful history. Hence, her optimal action is to revolt. Thus, the second citizen can be sure to observe a truthful history, so her optimal action is to act truthfully as is the case for any subsequent individual. Citizens at any position can be sure to observe a truthful history to which the unique strategy that is not strictly dominated is to be truthful. Notice that no such history can be reached that is not covered by our reasoning above. All these arguments make clear that under the social media technology the revolution always succeeds because each willing individual revolts in any perfect Bayesian Nash equilibrium.

Mass media

Proof Given the number of previous revolts, a willing individual revolts if she can be sure that there are enough willing citizens after her and enough of them will revolt as well. Any willing individual at a position above $\xi-1$ cannot be sure that among the rest of the citizens who have not decided yet there is a willing individual. Thus, any willing individual who is at position $[\xi, n]$ will revolt only when observing at least $t-1$ revolts. A willing individual at position $\xi-1$ knows that there is at least one more willing citizen behind her who will surely revolt if she observes at least $t-1$ revolts. Therefore, a willing individual at position $\xi-1$ will revolt if she observes at least $t-2$ revolts, since then she can be sure that the revolution triumphs. The same is true for any willing individual at position $[2 \xi-n-2, \xi-1]$, since willing citizens at these positions know that there are at least two willing individuals behind them, but they cannot make sure that the first of these willing individuals can be sure that there is another willing individual behind her. If the revolution fails, the sanction can be execution and that is why a willing individual wants to avoid the worst scenario.

The previous reasoning can be generalized. In the position interval $[\xi, n]$ willing individuals can be certain to increase the number of protesters by 1 for sure: by revolting themselves. When at a position $[(\xi-1)-(n-\xi+1), \xi-1]$ a willing individual knows that she can increase the number of those who revolt by 2: if she revolts, she can induce a willing individual behind her as well. At any position $[(\xi-1)-2(n-\xi+1)-1,(\xi-1)-(n-\xi+1)-1]$. Note that the length of the intervals is $n-\xi+1$. Since there are $n$ individuals, starting from the last one we can have $\left[\frac{n}{n-\xi+1}\right]$ such intervals. If there is a willing individual is at positions $\left[1, n-\left[\frac{n}{n-\xi+1}\right]\right]$, then she can be sure that if she revolts, then she can induce other willings to revolt and in the end there will be $\left[\frac{n}{n-\xi+1}\right]+1$ revolts. 
If no willing individual is at positions $\left[1, n-\left[\frac{n}{n-\xi+1}\right]\right]$, then a rational willing citizen infers that with a threshold of $\left[\frac{n}{n-\xi+1}\right]+1$ if no revolts are observed at positions $\left[1, n-\left[\frac{n}{n-\xi+1}\right]\right]$, then it is due to the fact that those positions are taken by unwilling individuals. However, in this case she can make sure that there enough willing citizens behind, so she joins the revolt. The previous points show how we obtain the condition on the threshold that determines if a revolution is successful under mass media. In Example 2 we show that if these conditions are not met, then the revolution may fail.

\section{Appendix C}

Figure 2 represents the complete decision tree for the case of social media. Individuals are able to distinguish the sequence of actions but they do not know the type vector. For simplicity, the information nodes that belong to the same information set for individuals in position 3 and 4 have been marked with the same geometrical shape. 


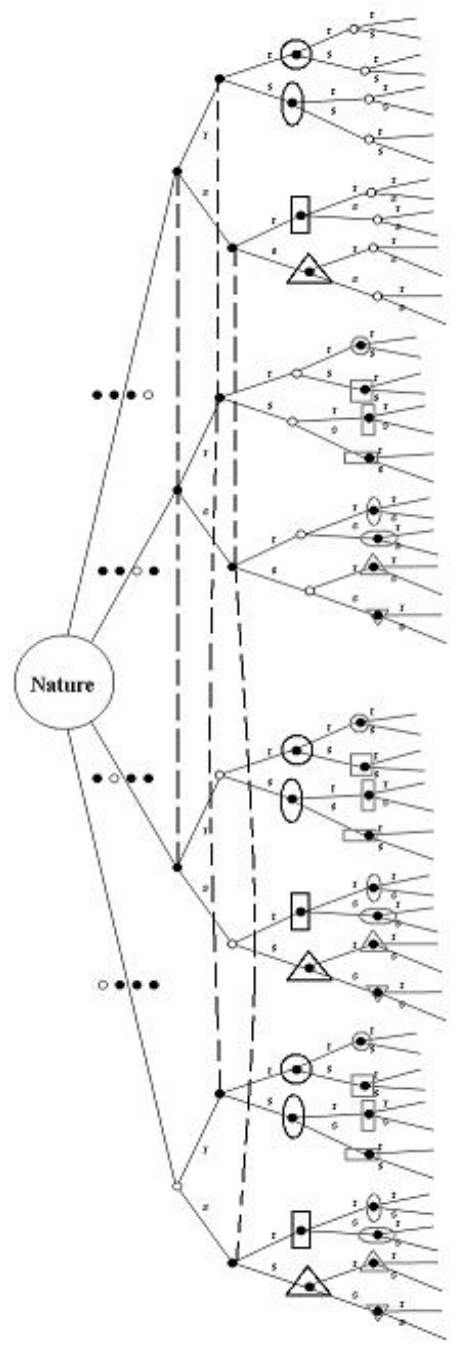

Figure 2. Decision tree of the social media case in Example 1 